\title{
Conditions of Generating Descriptive Image Algebras by a Set of Image Processing Operations*
}

\author{
Igor B. Gurevich and Vera Yashina \\ Scientific Council "Cybernetics" of the Russian Academy of Sciences \\ 40, Vavilov str., 119991 Moscow GSP-1, Russian Federation \\ igourevi@ccas.ru, werayashina@mail.ru
}

\begin{abstract}
It is outlined new results of investigations into development of mathematical tools for analysis and estimation of information represented by images. It continues research of a new class of image algebras (IA) - the Descriptive Image Algebras (DIA). Practical implementation of DIA in image analysis applications requires a study of a set of operations, leading or not leading to DIA construction, having or not having physical interpretation. Operations of the ring in these algebras are both standard algebraic operations and special operations of image processing and transformation. The problem of operations that can be used for construction of DIA and of how this possibility is connected with physical interpretation of corresponding algebra operations is still open. This problem is reduced to formulation of the conditions that should be satisfied by a set of operations for construction of the DIA. The first stage of its solution is the construction of the examples of the sets of operations (having physical meaning), leading or not leading to DIA construction. The basic results of the report are both the method of testing the specified conditions and the examples of sets with various elements and the operations introduced on them (both generating algebras and not).
\end{abstract}

\section{Introduction}

The new results of investigations in the field of the development of mathematical apparatus for analysis and evaluation of information represented in the form of images are described in this paper. These studies have been conducted in the recent years at the Scientific Council "Cybernetics", Russian Academy of Sciences, and they are concerned with development and implementation of the Descriptive Approach to Image Analysis and Recognition [2]. A new class of image algebras (standard IA was described in [4], definition 1) is defined within this framework - Descriptive Image Algebras (DIA [3], definition 2). The main purpose of this investigation is construction of unifying theory that covers different transformations and operations of image analysis, processing and understanding. DIA generalizes some famous

\footnotetext{
* This work was supported in part by the Russian Foundation for Basic Research (project nos. 01-07-90016 and 02-01-00182) and RAS (project no. 10002-251/P-16/097-025/310303-0 of the Complex Program of Scientific Research of the Presidium of RAS "Mathematical Modeling, Intellectual Systems, and Control of the Nonlinear Mechanical Systems").
} 
mathematical theory and the algebraic specificity of DIA is defined by the fact that the elements of the ring include both the models of images and the operations on images. This specific of DIA provides the effective synthesis and implementation of the basic procedures of formal image description, processing, analysis, and recognition. So the developed algebraic tools can help to solve many problems related to intellectual computer systems and to automatization of image-based decision making (i.e. design of systems for automated image processing and analysis, design of systems for automation of scientific research, high quality medical and technical diagnostics, ecological monitoring, remote sensing, non-destructive testing, quality control, etc). Useful practical implementation of new algebra is also development of language for comparison and standardization of different algorithms for image analysis, recognition and processing.

The practical implementation of DIA in image analysis applications requires research of the set of operations, leading or not leading to DIA construction, having or not having physical interpretation. Operations of the ring in these algebras can be both standard algebraic operations and special operations of image processing and transformation. The problem of operations that can be used for construction of DIA and of how this possibility is connected with physical interpretation of corresponding algebra operations is still open. Thus, the following problems appear: (a) to define the class of the allowable operations, having physical meaning; (b) to define the class of the allowable operations having no physical meaning; (c) to define the class of the operation (both having physical meaning and not), which do not lead to the construction of algebras. In the whole, this problem is reduced to formulation of the conditions that should be satisfied by a set of operations for DIA construction.

The first stage is the construction of the examples of the sets of operations (having physical meaning), which lead (or not) to DIA construction. The basic results of the paper are (a) 2 examples of the basic DIA having one ring with various elements and operations of a certain physical meaning: in the example 2 the elements of the ring are images; in the example 3 the elements of the ring are binary operation on images; (b) the example 4 where the constructed set of elements with operations introduced over it is an additive group.

The following lines of research dating back to $1970 \mathrm{~s}-80 \mathrm{~s}$ contributed to the development of DIA: (a) the Algebra of Zhuravlev (Yu.Zhuravlev and his scientific school [6]); (b) the Descriptive Approach for Image Analysis and Understanding (I.Gurevich [2]); (c) the General Pattern Theory developed by U.Grenander [1]; (d) the extended image algebra developed by G.Ritter [4]. 


\section{Images and Operations on Images. The Main Conceptions and Definitions}

\subsection{Basic Definitions}

Definition 1: Algebra over field A is called IA, if the elements of its ring are images (sets of points) and the values and properties associated with these images.

Definition 2: Algebra over field A is called DIA, if the elements of its ring are either the models of images (including images themselves and the values and properties associated with these images), or operations on images, or both the models and operations.

Definition 3: DIA is called a basic DIA, if its ring consists either of the image models or of the operations on images.

For generality of the results, during construction of examples we use the definition of an image (see Definition 4) and the operations on images, introduced by G. Ritter in [4].

Definition 4: Let $\mathrm{F}$ be a set of values and $\mathrm{X}$ be a set of points. An F-valued image on $\mathrm{X}$ is any element of $\mathrm{F}^{\mathrm{X}}$ (i.e., $\mathrm{a}: \mathrm{X}-\mathrm{F}$ ):

$I=\{(x, a(x)), x \in X, a(x) \in F\}$.

\subsection{Operations on Images ([4])}

Let $I_{1}=\{(x, a(x)), x \in X\}, I_{2}=\{(x, b(x)), x \in X\}$ and let the following operations be defined on the set $\mathrm{F}$ : operations of addition, multiplication, finding the maximum and inverse operations of difference, division, finding the minimum, and the operation of raising to power $(\forall \mathrm{a}(\mathrm{x}), \mathrm{b}(\mathrm{x}) \in \mathrm{F} \exists$ ! $\mathrm{a}(\mathrm{x})+\mathrm{b}(\mathrm{x}) ; \exists$ ! $\mathrm{a}(\mathrm{x}) * \mathrm{~b}(\mathrm{x}) ; \exists ! \mathrm{a}(\mathrm{x}) \vee \mathrm{b}(\mathrm{x}) ; \exists ! \mathrm{a}(\mathrm{x})-\mathrm{b}(\mathrm{x})$; $\exists ! \mathrm{a}(\mathrm{x}) \wedge \mathrm{b}(\mathrm{x})$; for $\mathrm{b}(\mathrm{x}) \neq 0 \exists$ ! $\mathrm{a}(\mathrm{x}) / \mathrm{b}(\mathrm{x})$; for $\mathrm{a}(\mathrm{x})>0 \exists$ ! $\left.\mathrm{a}(\mathrm{x})^{\mathrm{b}(\mathrm{x})}\right)$.

The basic operations on images from $\mathrm{F}^{\mathrm{x}}$ are the pointwise addition, multiplication, and finding the maximum respectively:

(1) $I_{1}+I_{2}=\{(x, c(x)), c(x)=a(x)+b(x), x \in X\}$;

(2) $\mathrm{I}_{1} * \mathrm{I}_{2}=\{(\mathrm{x}, \mathrm{c}(\mathrm{x})), \mathrm{c}(\mathrm{x})=\mathrm{a}(\mathrm{x}) * \mathrm{~b}(\mathrm{x}), \mathrm{x} \in \mathrm{X}\}$;

(3) $I_{1} \vee I_{2}=\{(x, c(x)), c(x)=a(x) \vee b(x), x \in X\}$..

The operations of difference, division, and finding the minimum are introduced as operations inverse to addition, multiplication, and finding the maximum respectively:

(4) $\mathrm{I}_{1}-\mathrm{I}_{2}=\{(\mathrm{x}, \mathrm{c}(\mathrm{x})), \mathrm{c}(\mathrm{x})=\mathrm{a}(\mathrm{x})-\mathrm{b}(\mathrm{x}), \mathrm{x} \in \mathrm{X}\}$;

(5) $\frac{I_{1}}{I_{2}}=\left\{(x, c(x)), c(x)=\frac{a(x)}{b(x)}, b(x) \neq 0, c(x)=0, b(x)=0\right\}$;

(6) $I_{1} \wedge I_{2}=\{(x, c(x)), c(x)=a(x) \wedge b(x), x \in X\}$.

Similarly, we may introduce other operations on images:

(7) $\mathrm{I}_{1}^{\mathrm{I} 2}=\left\{(\mathrm{x}, \mathrm{c}(\mathrm{x})), \mathrm{c}(\mathrm{x})=\mathrm{a}(\mathrm{x})^{\mathrm{b}(\mathrm{x})}\right.$, if $\mathrm{a}(\mathrm{x})>0$, otherwise $\left.\mathrm{c}(\mathrm{x})=0, \mathrm{x} \in \mathrm{X}\right\}$.

We may introduce unary operations: for example, multiplication by an element from the field of real numbers $(\alpha \in R): \alpha I_{1}=\{(x, c(x)), c(x)=\alpha a(x), x \in X\}$ 


\section{Conditions of Membership in DIA-Class: Checking Satisfiability}

\subsection{Examples of Sets of Operations Which Generate an Algebra}

Various sets $U$ with the operations of addition, multiplication and multiplication by the element from the field of real numbers introduced on them are considered.

1. The elements of the set $\mathrm{U}$ :

1.1 Images, defined on the set $\mathrm{X}$ with an arbitrary range of values $\mathrm{F}$ of the dimension equal to the dimension of the set $\mathrm{X}$, i.e. $\mathrm{X}, \mathrm{F} \subset \mathrm{R}^{\mathrm{n}}$;

1.2 Images, defined on the set $\mathrm{X}$ with the range of values $\mathrm{X}, \mathrm{X} \subset \mathrm{R}^{\mathrm{n}}$;

1.3 Standard binary operations on images [4].

2. Operations on the set elements (2.1,2.2,2.3): addition; multiplication; multiplication by an element from the field of real numbers.

3. Physical meaning of the operations:

3.1. (a) addition - total brightness of two images; (b) multiplication - pointwise filter; (c) multiplication by an element from the field of real numbers - proportional increase or decrease in image brightness.

3.2. (a) addition - total brightness of two images; (b) multiplication - (b1) global (non-pointwise) filter; (b2) definition of one image on a set defined by the other image; (c) multiplication by an element from the field of real numbers - a proportional increase or decrease in image brightness.

3.3. (I) addition -global filter: first two operations are applied to both images; then result images are added; (b) multiplication - global filter: the second operation is applied to both images; the first and the second operands of the first operation are the result of applying second operation; (c) multiplication by an element from the field of real numbers -multiplication of an image by an element from the field of real numbers (unary operation on the image - a standard operation of the multiplication of an image by an element of the field of real numbers [4]).

Below, we give the examples of the DIA, generated by the sets U with the specified characteristics (the types of set elements and operations together with their physical interpretation are specified in parentheses according to the list given above). Proof of DIA generation by the set $U$ with the operations of addition, multiplication and multiplication by the element from the field of real numbers introduced on them is based on checking algebra properties. (definition of algebra is in [5]). Example 1 (1.1, $2.1,3.1$ ) is omitted due to space limitations.

\section{Example 2: (2.1, 2.2, 2.3).}

Suppose that:

- $\mathrm{R}$ is a field of real numbers;

- $I=\{(x, f(x)), x \in X, f(x) \square \in X\}\left(X \subset R^{n}, n \in N\right)$;

- $\mathrm{I}_{1}=\{(\mathrm{x}, \mathrm{a}(\mathrm{x})), \mathrm{x} \in \mathrm{X}, \mathrm{a}(\mathrm{x}) \in \mathrm{X}\}, \mathrm{I}_{2}=\{(\mathrm{x}, \mathrm{b}(\mathrm{x})), \mathrm{x} \in \mathrm{X}, \mathrm{b}(\mathrm{x}) \in \mathrm{X}\}$; 
- the operation of addition of two elements from $X$ is introduced: $i, j=1,2, \ldots \forall \mathrm{a}(\mathrm{x})$, $\mathrm{b}(\mathrm{x}) \in \mathrm{X}: \exists$ ! $\mathrm{a}(\mathrm{x})+\mathrm{b}(\mathrm{x}) \in \mathrm{X}$; this operation satisfies some conditions $(\forall \mathrm{a}(\mathrm{x}), \mathrm{b}(\mathrm{x})$, $\mathrm{c}(\mathrm{x}) \in \mathrm{X})$ :

$2.1 \mathrm{a}(\mathrm{x})+(\mathrm{b}(\mathrm{x})+\mathrm{c}(\mathrm{x}))=(\mathrm{a}(\mathrm{x})+\mathrm{b}(\mathrm{x}))+\mathrm{c}(\mathrm{x})$;

$2.2 \mathrm{a}(\mathrm{x})+\mathrm{b}(\mathrm{x})=\mathrm{b}(\mathrm{x})+\mathrm{a}(\mathrm{x})$;

$2.3 \forall \mathrm{a}(\mathrm{x}) \in \mathrm{X}, \exists 0 \in \mathrm{X}: \mathrm{a}(\mathrm{x})+0=\mathrm{a}(\mathrm{x})$;

$2.4 \forall \mathrm{a}(\mathrm{x}) \in \mathrm{X}, \exists(-\mathrm{a}(\mathrm{x})) \in \mathrm{X}: \mathrm{a}(\mathrm{x})+(-\mathrm{a}(\mathrm{x}))=0$;

- the operation of superposition of two elements from $\mathrm{X}$ is introduced: $\forall \mathrm{a}(\mathrm{x}), \mathrm{b}(\mathrm{x}) \in$ $\mathrm{X}: \exists ! \mathrm{a}(\mathrm{b}(\mathrm{x})) \in \mathrm{X}$;

- the operation of multiplication by the element of the field $\mathrm{R}$ is introduced on the set $\mathrm{X}: \forall \alpha \in \mathrm{R}, \mathrm{a}(\mathrm{x}) \in \mathrm{X}: \exists ! \alpha \mathrm{a}(\mathrm{x}) \in \mathrm{X}$; this operation satisfies some conditions $(\forall \mathrm{a}(\mathrm{x})$, $\mathrm{b}(\mathrm{x}), \mathrm{c}(\mathrm{x}) \in \mathrm{X}, \forall \alpha, \beta \in \mathrm{R})$ :

$2.5(\alpha \mathrm{a}(\mathrm{x})+\beta \mathrm{b}(\mathrm{x})) \mathrm{c}(\mathrm{x})=\alpha \mathrm{a}(\mathrm{x}) \mathrm{c}(\mathrm{x})+\beta \mathrm{b}(\mathrm{x}) \mathrm{c}(\mathrm{x})$;

$2.6 \alpha(\beta \mathrm{a}(\mathrm{x}))=\alpha \beta \mathrm{a}(\mathrm{x})$;

$2.7(\alpha+\beta) \mathrm{a}(\mathrm{x})=\alpha \mathrm{a}(\mathrm{x})+\beta \mathrm{a}(\mathrm{x})$;

$2.8 \alpha(\mathrm{a}(\mathrm{x})+\mathrm{b}(\mathrm{x}))=\alpha \mathrm{a}(\mathrm{x})+\alpha \mathrm{b}(\mathrm{x})$.

(So we can notice, that set $\mathrm{X}$ is vector field on field $\mathrm{R}$ (properties 2.1-2.4, 2.7, 2.8)).

Let us introduce

- operation of addition of two images $\mathrm{I}_{1}, \mathrm{I}_{2}$ :

$\mathrm{I}_{1}+\mathrm{I}_{2}=\{(\mathrm{x}, \mathrm{a}(\mathrm{x})+\mathrm{b}(\mathrm{x})), \mathrm{x} \in \mathrm{X}\}$;

- operation of multiplication of two images $\mathrm{I}_{1}, \mathrm{I}_{2}$ :

$\mathrm{I}_{1} * \mathrm{I}_{2}=\{(\mathrm{x}, \mathrm{a}(\mathrm{b}(\mathrm{x}))), \mathrm{x} \in \mathrm{X}\}$ (this operation leaves us in the set $\left.\mathrm{X}\right)$;

- operation of the multiplication of image I by an element of the field of the real number $\alpha \in \mathrm{R}$ :

$\alpha \mathrm{I}=\{(\mathrm{x}, \alpha \mathrm{f}(\mathrm{x})), \mathrm{x} \in \mathrm{X}\}$.

All properties of the ring, field, and vector space are satisfied, thus, the created construction is algebra.

\section{Example 3: (1.3, 2.3, 3.3).}

Suppose that

- $\mathrm{R}$ is a field of real numbers;

- the elements of a set $U$ are the binary operations on images [4];

- A,B,C... are the images, transforming $\mathrm{X}$ into $\mathrm{X}, \mathrm{X} \subset \mathrm{R}^{\mathrm{n}}$;

- operations on images are introduced [4];

- $\mathrm{r}_{1}, \mathrm{r}_{2}, \ldots \in\left\{+,{ }^{*}, \vee, \wedge,-, \backslash, \mathrm{A}^{\mathrm{B}}\right\}$, i.e., $\mathrm{r}_{1}, \mathrm{r}_{2}, \ldots$ are the operations on two images;

- $\mathrm{r}(\mathrm{A}, \mathrm{B})$ is the image after applying the operation $\mathrm{r}$ on images $\mathrm{A}$ and $\mathrm{B}$.

Let us introduce

- operation of addition of two operations $\mathrm{r}_{1}, \mathrm{r}_{2}$ : $\left(r_{1} \oplus r_{2}\right)(A, B)=r_{1}(A, B)+r_{2}(A, B)$

- operation of multiplication of two operations $r_{1}, r_{2}$ : $\left(r_{1} \otimes r_{2}\right)(A, B)=r_{1}\left(r_{2}(A, B), r_{2}(A, B)\right)$;

- operation of the multiplication of the operation $r$ by an element of the field of the real number $\alpha \in \mathrm{R}:(\alpha \mathrm{r})(\mathrm{A}, \mathrm{B})=\alpha \mathrm{r}(\mathrm{A}, \mathrm{B})$ (the right part means the multiplication of an image by the element of the field). 
All properties of the ring, field, and vector space are satisfied, thus, the created construction is algebra.

\subsection{Examples of Sets of the Operations Which Do Not Provide Generation of Algebra}

Similarly to Section 3.1 , various sets $U$ are considered with operations of addition, multiplication, and multiplication by the element from the field of real numbers introduced on them.

1. The elements of the set $\mathrm{U}$ :

1.4 Images, defined on the set $\mathrm{X}$ with arbitrary range of values $\mathrm{F}$ of the dimension equal to the dimension of the set $\mathrm{X}$, i.e. $\mathrm{X}, \mathrm{F} \subset \mathrm{R}^{\mathrm{n}}$;

1.5 Images, defined on arbitrary set $X_{i}$ with arbitrary range of values $F_{i}$ of the dimension equal to the dimension of the set $X_{i}$, i.e. $X_{i}, F_{i} \subset R^{n}, i=1,2, \ldots$

2. Operations on the elements of a set $(2.4,2.5)$ : addition, multiplication, and multiplication by an element from the field of real numbers.

3. Physical meaning of the operations:

3.4 (a) addition - total brightness of two images; (b) multiplication - (b1) global (non- pointwise) filter; (b2) definition of one image on a set defined by the other image (in the case when this operation is not determined ( $F \not \subset X)$, the value of the second operand is taken as a result of multiplication); (c) multiplication by an element from the field of real numbers - proportional increase or decrease in image brightness.

3.5 (a) addition - total brightness of two images on intersection of the sets on which these images are given; in the points of a set $\mathrm{X}$ where only one image is determined, it is considered as a result of the operation; (b) multiplication: (b1) global (non-pointwise) filter; in the points of a set X, where only one image is determined (first or second operands), the image (first or second operands, respectively) is considered as a result of the operation; (c) the multiplication by the element from the field of real numbers - proportional increase or decrease in image brightness.

Below, we give the examples of constructions, generated by the sets $U$ with the specified characteristics (the types of set elements and operations together with their physical interpretation are specified in parentheses according to the list given above). These constructions are not algebras. Example $(1.5,2.5,3.5)$ is omitted due to space limitations.

\section{Example 4 (1.4, 2.4, 3.4)}

Suppose that:

- $\mathrm{R}$ is the field of real numbers;

- $\mathrm{I}=\{(\mathrm{x}, \mathrm{f}(\mathrm{x})), \quad \mathrm{x} \in \mathrm{X}, \quad \mathrm{f}(\mathrm{x})] \in \mathrm{F}\} \quad\left(\mathrm{X}, \mathrm{F} \subset \mathrm{R}^{\mathrm{n}}, \quad \mathrm{n} \in \mathrm{N}\right) ; \quad \mathrm{I}_{1}=\left\{(\mathrm{x}, \mathrm{a}(\mathrm{x})), \quad \mathrm{x} \in \mathrm{X}, \quad \mathrm{a}(\mathrm{x}) \in \mathrm{F}_{1}\right\}$; $I_{2}=\left\{(x, b(x)), x \in X, b(x) \in F_{2}\right\}$, where $F_{1}$ and $F_{2}$ are ranges of values of images $I_{1}$ and $\mathrm{I}_{2}$, respectively, on the set $\mathrm{X}$; 
- the operation of addition of two elements from $F_{i}, F_{j} \subset R^{n}$ is introduced: $i, j=1,2, \ldots$, $\forall \mathrm{a}(\mathrm{x}) \in \mathrm{F}_{\mathrm{i}}, \mathrm{b}(\mathrm{x}) \in \mathrm{F}_{\mathrm{j}}: \exists$ ! $\mathrm{a}(\mathrm{x})+\mathrm{b}(\mathrm{x}) \in \mathrm{F}_{\mathrm{k}}, \mathrm{i}=1,2 \ldots, \mathrm{F}_{\mathrm{k}} \subset \mathrm{R}^{\mathrm{n}}$; this operation satisfies some conditions $\left(\forall \mathrm{a}(\mathrm{x}) \in \mathrm{F}_{\mathrm{i}}, \mathrm{b}(\mathrm{x}) \in \mathrm{F}_{\mathrm{j},} \mathrm{c}(\mathrm{x}) \in \mathrm{F}_{\mathrm{y}}, \mathrm{i}, \mathrm{j}, \mathrm{y}=1,2, \ldots\right)$ :

$\mathrm{a}(\mathrm{x})+(\mathrm{b}(\mathrm{x})+\mathrm{c}(\mathrm{x}))=(\mathrm{a}(\mathrm{x})+\mathrm{b}(\mathrm{x}))+\mathrm{c}(\mathrm{x})$;

$\mathrm{a}(\mathrm{x})+\mathrm{b}(\mathrm{x})=\mathrm{b}(\mathrm{x})+\mathrm{a}(\mathrm{x})$;

$\forall \mathrm{i}: \forall \mathrm{a}(\mathrm{x}) \in \mathrm{F}_{\mathrm{i}}, \exists 0 \in \mathrm{F}_{\mathrm{i}}: \mathrm{a}(\mathrm{x})+0=\mathrm{a}(\mathrm{x})$;

$\forall \mathrm{i}: \forall \mathrm{a}(\mathrm{x}) \in \mathrm{F}_{\mathrm{i}}, \exists(-\mathrm{a}(\mathrm{x})) \in \mathrm{F}_{\mathrm{i}}: \mathrm{a}(\mathrm{x})+(-\mathrm{a}(\mathrm{x}))=0$;

- the operation of superposition of two elements from $F_{i}, F_{j}$ is introduced: $i, j=1,2, \ldots$, $\forall \mathrm{a}(\mathrm{x}) \in \mathrm{F}_{\mathrm{i}}, \mathrm{b}(\mathrm{x}) \in \mathrm{F}_{\mathrm{j}}$, at the points, where $\mathrm{b}(\mathrm{x}) \in \mathrm{X}: \exists$ ! $\mathrm{a}(\mathrm{b}(\mathrm{x})) \in \mathrm{F}_{\mathrm{i}}$;

- the operation of multiplication by the element of the field $\mathrm{R}$ is introduced on the set F: $\forall \alpha \in R, a(x) \in F: \exists ! \alpha a(x) \in F$; this operation satisfies some conditions $\left(\forall \mathrm{a}(\mathrm{x}) \in \mathrm{F}_{\mathrm{i}}\right.$, $\left.\mathrm{b}(\mathrm{x}) \in \mathrm{F}_{\mathrm{j}, \mathrm{c}}(\mathrm{x}) \in \mathrm{F}_{\mathrm{y}}, \mathrm{i}, \mathrm{j}, \mathrm{y}=1,2, \ldots, \forall \alpha, \beta \in \mathrm{R}\right)$ :

- $(\alpha \mathrm{a}(\mathrm{x})+\beta \mathrm{b}(\mathrm{x})) \mathrm{c}(\mathrm{x})=\alpha \mathrm{a}(\mathrm{x}) \mathrm{c}(\mathrm{x})+\beta \mathrm{b}(\mathrm{x}) \mathrm{c}(\mathrm{x})$; $(\alpha+\beta) a(x)=\alpha a(x)+\beta a(x) ; \alpha(a(x)+b(x))=\alpha a(x)+\alpha b(x)$.

$\alpha(\beta \mathrm{a}(\mathrm{x}))=\alpha \beta \mathrm{a}(\mathrm{x})$

Let us introduce:

- the operation of addition of two images $\mathrm{I}_{1}, \mathrm{I}_{2}$ :

$\mathrm{I}_{1}+\mathrm{I}_{2}=\{(\mathrm{x}, \mathrm{a}(\mathrm{x})+\mathrm{b}(\mathrm{x})), \mathrm{x} \in \mathrm{X}\}$;

- the operation of multiplication of images $\mathrm{I}_{1}, \mathrm{I}_{2}$ :

$$
\mathrm{I}_{1} * \mathrm{I}_{2}=\left\{\begin{array}{l}
(x, a(b(x))), b(x) \in X \\
(x, b(x)), b(x) \notin X
\end{array} ;\right.
$$

- the operation of multiplication of image I by an element of the field of real numbers $\alpha \in \mathrm{R}$ :

$\alpha \mathrm{I}=\{(\mathrm{x}, \alpha \mathrm{f}(\mathrm{x})), \mathrm{x} \in \mathrm{X}\}$.

The created construction is not algebra - it is an additive group, because the associativity of multiplication operation is not satisfied and all properties of an additive group are satisfied (definition of group is in [5]).

\section{Conclusion}

The examples of sets with various elements and the operations introduced on them are considered both belonging to algebras and not. For constructing the examples, the standard operations on images are used to show that DIA covers mathematical constructions of the standard IA[4] which satisfies the conditions of algebra[5]. The examples mentioned in this paper are the first step in ordering the operations introduced on various sets, generating and not generating DIA. Further it is planned to precisely formulate necessary and sufficient conditions of DIA generation by the sets of considered type.

Our technique for formulating and checking the conditions for the set of operations that ensures the DIA construction is a basis for obtaining mathematically proven criterion for a choice of operations for producing efficient image analysis and recognition algorithmic schemes. This criterion is useful for practical implementation. 


\section{References}

1. Grenander, U.: General Pattern Theory. A Mathematical Study of Regular Structures, Oxford: Clarendon Press (1993)

2. Gurevich, I.B.: The Descriptive Framework for an Image Recognition Problem, Proc. of the $6^{\text {th }}$ Scandinavian Conf. on Image Analysis, Oulu, Finland, Vol.1(Pattern Recognition Society of Finland) (1989) 220-227

3. Gurevich, I.B., Smetanin, Yu.G., Zhuravlev, Yu.I.: Descriptive Image Algebras: Determination of the Base Structures, Pattern Recognition and Image Analysis, Vol. 9, No.4 (1999) 635-647

4. Ritter, G.X., Wilson, J.N.: Handbook of Computer Vision Algorithms in Image Algebra, 2-d Edition. CRC Press Inc. (2001)

5. Van Der Waerden, B.L.: Algebra I,II, Springer-Verlag, Berlin Heidelberg New York (1971, 1967(in Russian))

6. Zhuravlev, Yu.I.: Correct Algebras Over Sets of Incorrect (Heuristic) Algorithms, Cybernetics (Kiev), N. 4. (1977) 14-21, N. 6. (1977) 21-27, N. 2. (1978) 35-42, (in Russian) 